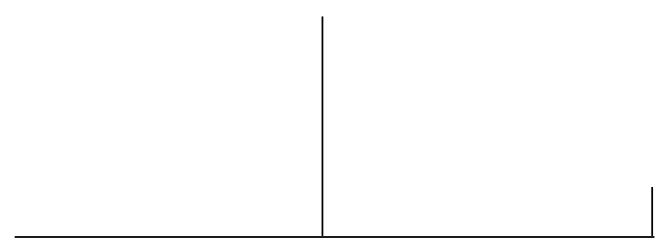

Rev. Latinoam. Psicopat. Fund., São Paulo, v. 13, n. 4, p. 617-634, dezembro 2010

\title{
Urgência subjetiva do neonato em UTI
}

Angela Vorcaro

\begin{abstract}
O artigo tem por objetivo questionar alguns discursos sobre os primórdios da estruturação do sujeito para, posteriormente, construir hipóteses sobre o que estaria em jogo na experiência do neonato prematuro na UTI. Para tal, à condição do organismo biológico e às intervenções médicas oporemos as funções da fala e da linguagem como determinantes do que será constituído como trauma. Além disso, discutiremos como abordar a questão do tempo nos processos de subjetivação levados a cabo pela criança.
\end{abstract}

Palavras-chave: Neonato, psicanálise, UTI, linguagem, trauma, tempo 
É certo que a nós, neuróticos, interroga sobremaneira - e também nos fascina - o que se cristaliza numa introdução atípica do bebê no mundo, ou seja, aquilo que seria o instante do nascimento perdura sem solução marcado por uma obscuridade insensata: a sobrevivência mantém-se interrogada, e o nascimento, longe de estabelecer a vida de uma criança, é apenas o início de um longo procedimento médico-tecnológico que mantém suspensa a definição de vida e de morte para aquele ser. Só a saída da UTI completará um circuito no qual, finalmente, pode-se contar com a vida da criança.

Como considerar a experiência dessas crianças e fazê-las falar, trazendo-as para o simbólico? Como dizer melhor da aparente des-humanidade que incide nessa técnica de sobrevivência que praticamente isola a criança dos laços sociais primários imprescindíveis a sua subjetivação?

Tentamos localizar o que efetivamente está em jogo na entrada de uma criança no mundo e o que precisa ou não deve ser adiado (Vorcaro, 2002; Jerusalinsky, 2002; Zornig, 2006; Sanson, 2006; Bernardino, 2008). Temos voltado aos primórdios da estruturação do sujeito e a suas claudicações, para construir hipóteses sobre o que estaria em jogo na experiência do neonato prematuro na UTI, onde supomos que seus processos de subjetivação serão protelados (Battikha, 2001; Dias, 2004; Catão, 2004; Rabello, 2004; Bleichmar, 2006).

Já interrogamos as modalidades pelas quais o organismo do neonato, diante do extraordinário afluxo de tensão sem qualquer apaziguamento maternante, poderá vir a constituir o trilhamento de vias de elaboração desse desamparo primário. É o que se desdobra em questões tais como: quando posteriormente o bebê for afetado pelas condições de angústia necessárias a sua constituição, esta será alheia aos acontecimentos primários em seu organismo, ou carregará seus traços? O que fica em suspensão no psiquismo do bebê em situação de risco de vida, submetido a tratamento cirúrgico devido a uma malformação congênita cardíaca ou neurológica? Há consequências psíquicas desse tratamento cirúrgico? (Martins e Vorcaro, 2008).

Muitos aspectos desse processo, a partir do ponto de vista materno, são alvo de estudos diversos que orientam práticas da psicanálise nos serviços intensivos (Krodi, 2008). A coincidência entre o nascimento do filho e o processo de deslocamento da posição de mulher para a de mãe podem colocar em xeque o saber materno ainda a ser instituído singularmente, produzindo

Rev. Latinoam. Psicopat. Fund., São Paulo, v. 13, n. 4, p. 617-634, dezembro 2010 
dificultadores para as operações da função de instauração subjetivante pelo agente materno. A antecedência e a permanência do saber técnico-científico anônimo sobre o saber materno específico pode, muitas vezes, criar um confronto no qual os procedimentos técnicos urgentes para a sobrevivência orgânica vão imperar sobre a constituição psíquica. O saber técnico, com seus imperativos científicos, pode, de acordo com a condição subjetiva materna, imobilizar a função simbólica do saber maternante singular na situação da internação hospitalar. Constata-se, muitas vezes, que essa imobilidade do saber maternante pode manter-se posteriormente, sem que a mãe - responsável primário pela singularização da transmissão simbólica - recubra e ressignifique o saber anônimo dos aparelhos e dos aparatos técnicos por meio do seu funcionamento transitivista (Bergés e Balbo, 2004). A identificação da mãe com a impotência do filho pode ser de tal monta que ela incorpora e faz prevalecer essa impotência (Vorcaro, 1998). São hoje bastante conhecidos os efeitos iatrogênicos da internação prolongada do filho sobre a mãe, quando, a partir dessa internação, a mãe desautoriza-se do exercício do transitivismo, por meio do qual, além de reconhecer nas manifestações da criança seus próprios estados, vai responder à criança e apaziguá-la. A partir do momento em que se reconhece impotente para ressignificar o mal-estar de seu filho e para discernir a alçada de seus cuidados de uma urgência hospitalar, essa mãe dá consistência a um filho desamparado de recursos simbólicos para circunscrever esse mal-estar e dependente de cuidados especializados para enfrentar qualquer situação que o afete (Coriat, 1997, p. 170). Ele passa a integrar o grupo de crianças chamadas de filhas do hospital.

Entretanto, essas considerações muitas vezes acabam por constituir equívocos teóricos baseados no fato de se confundir esse efeito dito traumático sobre a mãe - posteriormente transposto e atualizado em seu laço com a criança -, com um efeito da situação de internação sobre a própria criança. É relevante questionar se tal efeito é da ordem do traumático: a insuficiência da mãe em sustentar a função maternante será capaz de significar retroativamente o que teria sido da ordem do traumático para o filho? Mesmo que marque a história imaginária dessa criança, isso não implica necessariamente que o seja, efetivamente, para a criança.

É por isso que se faz necessário problematizar as implicações do procedimento de internação e de isolamento nos primeiros dias de vida, tomando o próprio neonato como referência. Encontramos, na literatura, um vácuo de abordagens a essa questão, a despeito de, nas práticas sistemáticas, ser senso comum considerar, a partir da concepção do nascimento como causador de traumatismo psíquico, que o neonato estaria, numa UTI, em estado psíquico de constante e desmedida angústia. Essa ideia remonta às observações de Otto Rank, no livro de 1923, The trauma of birth (citado por Freud 1976 [1925]), que afirma 


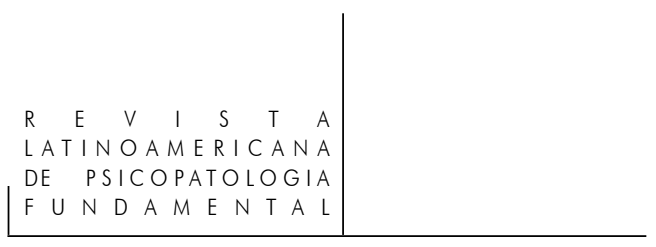

que o processo do nascimento seria a primeira situação de perigo, e a convulsão econômica, por ele produzida, tornar-se-ia o protótipo da reação de angústia.

Muitas atividades ditas de "humanização hospitalar" encontram seu paradigma na transposição da perspectiva rankiana, que perduraria numa UTI. Se, por um lado, as propostas daí advindas contribuem efetivamente para que os cuidados médicos específicos considerem a condição geral da criança (como, por exemplo, o amortecimento de choques e maiores cuidados com procedimentos invasivos); por outro lado, acabam esbarrando, novamente, no estabelecimento de procedimentos padronizados que mantêm e apenas repetem o funcionamento da criança no mesmo anonimato, na medida em que acabam por inserir a presença materna em um programa técnico a ser cumprido a despeito de quaisquer condições: a obrigatoriedade da presença materna, da amamentação etc. (Lima, Santos, Sampaio, Amorim, Toscano e Leal, 2001; Vorcaro e Lopes, 2006).

Entretanto, o argumento de Rank é desqualificado pelo próprio Freud (1925), que lhe responde afirmando que:

... nenhum conjunto de provas foi coligido para indicar que o nascimento difícil e retardado coincide de fato com o desenvolvimento de uma neurose, ou mesmo que as crianças assim nascidas exibem os fenômenos da primeira apreensão infantil de forma mais acentuada e por um período mais longo do que outras crianças. (p. 175-176)

Sem desconsiderar que o organismo possa ser invadido por uma tensão demasiada na situação de nascimento, Freud (1925) considera que o efeito dessa situação só terá chances de ocorrer a partir do que for posteriormente subjetivado pelo que o sujeito vier a viver depois, em sua experiência psíquica:

... estamos impedidos de fazer uso de tal dessa correlação pelo fato de que o nascimento não é experimentado subjetivamente como uma separação da mãe, visto que o feto, sendo uma criatura completamente narcísica, está totalmente alheio a sua existência como um objeto. (p. 154)

Em contraponto a posições radicais que localizam na UTI uma vivência de desamparo intenso e consequentemente de angústia desmedida, muitos médicos afirmam, a partir de sua prática junto ao bebê cirúrgico, que os anestésicos e sedações constantes destituem qualquer incidência de dor que chegue ao ponto de traumatizar (Martins e Vorcaro, 2007).

As controvérsias quanto aos modos de cuidado psíquico do neonato internado encontram sua base numa concepção de desenvolvimento orgânico em sua correlação com a estruturação psíquica. E podemos notar que tal concepção não é unânime e depende, não apenas das referências teóricas dos profissionais, mas também dos modos como transformam a teorização em um saber tácito imaginário que acaba fazendo prevalecer, mais do que o efeito da UTI sobre o neona-

Rev. Latinoam. Psicopat. Fund., São Paulo, v. 13, n. 4, p. 617-634, dezembro 2010 
to, o efeito da UTI sobre o observador. Por isso, podemos argumentar aqui que as insistentes perguntas sobre os efeitos psíquicos iatrogênicos da internação de neonatos em UTIs permitem supor faltar-nos a unidade de medida a partir da qual poderíamos fazer avançar uma prática psicanalítica no hospital.

Como Fernandes (2003) já apontou, há uma insistente demanda social da prevenção, desveladora do fantasma de intervir a tempo de evitar o indesejável. Essa característica "futurologista" da prevenção, mesmo incompatível com a psicanálise, implica um debate sistemático entre psicanalistas, quando se trata do bebê. Para a autora: “... a ação de pre-venir é a de 'chegar antes', é querer mirar o futuro, mas apoiando-se no passado. Leva em consideração as noções de previsão e probabilidade e está inseparável de uma dimensão política". Há uma relação intrínseca da prevenção com o ideal, retratando o incômodo social gerado pela infância quando esta não encarna o ideal de uma promessa de um ser pleno de possibilidades (Vorcaro, 1997).

Fernandes adverte-nos sobre a possibilidade de considerarmos as noções lacanianas de antecipação e de pressa como temporalidades que contribuem para o debate sobre a prevenção. Pode-se trabalhar com esse tempo da "pressa", sem que este se torne, como diz a autora, o tempo de uma adivinhação, de uma concordância generalizada, ou mesmo da predestinação que realiza, sem que se saiba, seu próprio imaginário sobre a criança.

Fernandes baseia-se nessa ideia de tempo para considerar a "prevenção ao avesso". Considerando essa questão do tempo, podemos dizer que há um ato que pode, na UTI, apressar-se para reconhecer o neonato como um sujeito, mesmo que este seja ainda muito incipiente, criando as condições que o supõem, para que ele - o sujeito - possa vir a comparecer com tenacidade. Trata-se do ato de fazer incidir a função da fala na relação técnica estabelecida junto ao neonato, numa UTI. Assim, qualquer um, em qualquer especialidade técnica - desde que não prive a criança da articulação entre o visto e o escutado por meio da concatenação linguageira desses indícios com as ações técnicas administradas junto à criança pode fazer aí o ato de invenção, suposição, antecipação e interpretação de um sujeito, incluindo-o em sua contagem. A exposição do neonato à articulação da fala a ele dirigida deve aí também se sobrepor, interceptando o exercício anônimo de protocolos técnicos de cuidado a que a criança está submetida na UTI. Não se desconhece que todo o aparato que cerca o neonato na UTI é feito de linguagem, mesmo que tal aparato restrinja-se ao que a condição de prematuridade orgânica do neonato pode tomar como oposição entre dois estados - de tensão e de apaziguamento - por meio do que a biunivocidade dos aparatos põe em marcha para a sobrevivência do neonato. Não se trata, portanto, apenas de expô-lo à linguagem, posto que ele já está nela, mas de banhá-lo dos efeitos que o ato da

Rev. Latinoam. Psicopat. Fund., São Paulo, v. 13, n. 4, p. 617-634, dezembro 2010 


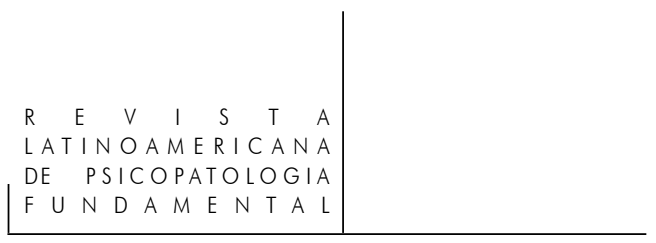

fala endereçada - mesmo que sem garantias - pode antecipar quanto ao engajamento com um ser de desejo.

Afinal, o essencial da lida cotidiana com a criança é fazer incidir a fala no corpo, pois, "essa gente que denominamos os homens, as mulheres eventualmente, vive na tagarelice" (Lacan, 1975, p. 11):

[É...] sempre com a ajuda das palavras que o homem pensa. E é no encontro dessas palavras com seu corpo que alguma coisa se esboça. (...) Se não houvesse palavras, de que o homem poderia testemunhar? É aí que ele coloca o sentido. (...) A linguagem intervém sempre sob a forma do que chamo, com uma palavra, que desejei que estivesse o mais próximo possível da palavra lalação alíngua. (...) Na alíngua, qualquer que seja ela, na qual alguém recebeu uma primeira marca, uma palavra é ambígua. (...) é pelo modo como alíngua foi falada e, também, entendida por fulano ou beltrano em sua particularidade, que alguma coisa em seguida reaparecerá nos sonhos, em todo tipo de tropeço, em todo tipo de formas de dizer. (...) O fato de que uma criança diga talvez, ainda não, antes mesmo de ser capaz de construir verdadeiramente uma frase, prova que há algo nela, uma peneira que se atravessa, por onde a água da linguagem chega a deixar algo na passagem, alguns detritos com os quais ela vai brincar, com os quais, necessariamente, ela terá que lidar. É isso que lhe deixa toda essa atividade não refletida - restos aos quais, mais tarde, porque ela é prematura, se agregarão os problemas do que a vai assustar. Graças a isso ela vai fazer a coalescência, por assim dizer, dessa realidade sexual e da linguagem. (Lacan, 1975, p. 6-16)

Vemos aí que é do encontro das palavras com o corpo que se trata, muito além da mera exposição à oposição de dois elementos, que prefiguram a estrutura mínima da linguagem. Para levar a cabo essa ideia - de produzir sistematicamente, na UTI, o ato de fala na relação com o neonato -, é preciso considerar o lugar a partir do qual tentamos ler as condições da criança nos primórdios da vida. Afinal, para evitar a instalação de rádio ou de televisão numa UTI é preciso diferenciar a reprodução eletrônica da fala de uma fala interpretativa dirigida especificamente a cada criança, "ao vivo", unplugged (fora da tomada). E isso exige que ressituemos as dimensões da realidade psíquica. Lacan (RSI, 10/12/74, inédito) nos lembra o embaraço que nos causa localizar a medida comum a partir da palavra outro.

Podemos considerar o outro a partir do que nos é exterior. Ele chama essa ideia de geometria do saco, ou seja, uma superfície com um interior que conteria o psiquismo (o próprio) e um exterior (o outro) que seria o mundo. Sistematicamente distinguimos o subjetivo do objetivo, quando situamos o ser humano como uma unidade com uma membrana limitadora entre um exterior e um interior. Com Winnicott (1951), para quem o indivíduo chega a um estádio de ser essa unidade, podemos dizer que isto se dá bem posteriormente ao nascimento, 
mas, com Lacan (1949), constatamos ainda que essa unidade, mesmo que seja suposta, é sempre precária, pois é restrita à instância do eu imaginário, que desconhece a estrutura que o faz existir. Ademais, longe de o outro ser localizável como o meio ambiente que é exterior ao ser, há outro outro que não tem a mínima relação com o interior/exterior e que exige uma interrogação rigorosa do modo como usamos os termos dentro e fora (1968-1969, p. 271-285). Sigamos seu raciocínio.

A concepção de representação, tal como proposta no idealismo, conduz ao equívoco de estabelecer a separação entre real (o fora) e representação (o dentro). Quando consideramos o organismo, o indivíduo biológico, parece evidente estabelecer um dentro e um fora. O dentro é aquilo que está no interior do envoltório da pele. $\mathrm{O}$ fora é todo o resto. Parece evidente também pensar que o que ele representa para si desse fora, ou seja, a sua imaginação, também deve estar no interior do envoltório da pele. A construção dessa representação de miragem é fundamentada na ótica, que forneceu o modelo da câmara escura para localizar a função do sujeito. ${ }^{1}$ Aí se apoia a ideia de que o psiquismo é situado num dentro limitado por uma superfície.

$\mathrm{Na}$ medida em que consideramos o campo do inconsciente, que não é um campo de fatos elementares, orgânicos, carnais, de impulsos biológicos, mas um campo que só se articula pela linguagem, é necessário interrogar o lugar do fora e do dentro. O que vem a ser aí a realidade?

Só ao sair da fascinação de conceber a representação unicamente no interior do corpo, poderemos analisar o que acontece no dentro e no fora, lembra Lacan (p. 276). E é isso que se pode perceber quando se considera o dinheiro que só serve para ser trocado: mesmo guardado em um cofre, esse dentro está completamente fora da essência do dinheiro, que é a de valer para a troca.

1. Segundo Lacan (2008 [1968-9], p. 275-6), o modelo da câmara escura dá o status da representação que cristalizou o núcleo do idealismo. Um espaço fechado, protegido de toda luz, onde somente um orifício se abre para o mundo externo. Quando esse mundo externo é iluminado, sua imagem se pinta e se agita na parede interna da câmara escura, conforme o que se passa do lado de fora. Onde quer que o furinho esteja colocado, sempre se reproduz, na câmara escura, uma imagem oposta ao furinho. É só pelo fato de que se abre esse pequeno orifício que se vê o mundo, ou seja, aquilo que está do lado de fora e que não passa de uma imagem, por só se traduzir como imagem do lado de dentro. Parece implícito nesse aparelho que, do que está do lado de fora, num espaço que não é limitado por nada, tudo em princípio pode vir a ter lugar no interior da câmara. No entanto, é patente que, se os furinhos se multiplicassem, já não haveria imagem em parte alguma.

Rev. Latinoam. Psicopat. Fund., São Paulo, v. 13, n. 4, p. 617-634, dezembro 2010 
O pensamento está nesse mesmo plano. O pensamento, ou seja, a concatenação significante, só tem valor na medida em que circula. $\mathrm{O}$ pensamento só é concebível ao ser articulado, ao se inscrever na linguagem, ao poder ser sustentado nas condições de um funcionamento dotado de regras. Não sabemos o que é um pensamento quando ele é guardado. A essência do pensamento está do lado de fora (p. 277).

Da mesma forma, é necessário distinguir ordens diferentes do que julgamos estar fora de nós, ou seja, do real. Por um lado, qualquer construção humana, por mais fora do corpo que esteja, é uma fabricação nossa, que dominamos, que humanizamos (p. 278).

Ao mesmo tempo, há coisas indizíveis que, mesmo podendo situar no que aparentemente seria dentro de nós, é muito mais exterior do que qualquer construção nossa; exterior porque, mesmo em nós, é para nós completamente estranha e desconhecida.

\section{Como considerar a distinção entre o neonato e a UTI para localizar como essa condição o afeta?}

Podemos conceber o organismo do neonato em um estado de total indiferenciação, que o impede distinguir o que o afeta de fora daquilo que o afeta de dentro do organismo. Reagindo apenas reflexamente aos estímulos que lhe são aplicados, sem localizar sua origem, o neonato usufrui a vida sem estabelecer nenhuma economia específica que lhe permitiria organizar a gestão desses estímulos. Sem diferenciar o que provém do próprio organismo do que provém do ambiente, o neonato e a UTI seriam uma mesma coisa pulsante em que ele poderia apenas distinguir dois estados opostos e complementares: tensão e apaziguamento, sem localizar a procedência desses estados. $\mathrm{O}$ fato de que o neonato não tenha condições de diferenciar o que vem do "interior" de seu organismo e as incidências que chegam do Umwelt em nada determina que ele não tenha condições de distinguir tensão e apaziguamento, pois suas próprias reações são, em um primeiro momento, reflexas.

Antes de prosseguirmos, voltemos a Lacan (p. 287), que nos lembra a modalidade pela qual os organismos subsistem, onde nada falta e nada (se) deseja porque funcionam instintivamente. Um saber apenas orgânico da subsistência indica ao organismo que dado elemento do seu meio ambiente é absorvível por ele, ou seja, é propício a sua preservação. Isso significa que o meio (Umwelt) é uma espécie de duplo do organismo. No animal, toda a ordem do meio é descritível em termos de adequação para a subsistência do indivíduo. Mesmo que esse meio

Rev. Latinoam. Psicopat. Fund., São Paulo, v. 13, n. 4, p. 617-634, dezembro 2010 
seja passível de falha, essa falha não é falta de nada, apenas dá início a uma sucessão de efeitos pelos quais o organismo se reduz, morrendo, levando consigo seu meio, sua miragem.

Diferentemente do organismo, o neonato depende de uma intermediação para sobreviver. Tal intermediação é chamada por Freud (1895) de ação específica, que ocorre quando a falha do funcionamento do organismo é reconhecida por alguém que exerce - sempre de um modo singular, mas tributária do saber da cultura o suprimento/suplemento que evita os efeitos da redução mortífera do organismo. Por isso, é possível dizer que o neonato humano só subsiste afetado pela ação específica do outro que carrega consigo (em seus gestos, em seus objetos, em sua fala) toda a ordem simbólica.

A questão é a modalidade pela qual as condições da UTI podem permitir a implantação primária dessa ordem simbólica nesse espaço indiferenciado quanto ao que é próprio ao bebê e ao que lhe é externo e que, posteriormente, situará a criança como singularidade e como pertencente ao campo simbólico.

Considerando o neonato como um sujeito completamente indeterminado, será preciso problematizar se os procedimentos da UTI permitem imprimir um funcionamento simbólico no qual, a partir da fala endereçada por alguém à criança, alguma marca seja localizável pelo neonato, situando uma estranheza nesse funcionamento pulsante da tensão/apaziguamento. Será necessário que essa fala endereçada e interpretativa de suas manifestações aleatórias intercepte o funcionamento do contínuo tensão/apaziguamento, de modo a possibilitar ao neonato diferenciar (ou seja, ler) um traço de exterioridade ao contínuo em que está imerso. Tal diferenciação de um traço de estranheza imprimirá o vestígio de que algo passou por ali. Entretanto, só a repetição diferencial dessa experiência distinguirá o traço da marca natural tensão/apaziguamento. A repetição diferencial de falas endereçadas à criança permite que outros traços e seus vestígios sejam reconhecidos por ela, estabelecendo uma rede em que estes se suportam, ou seja, na medida em que o primeiro traço discernível for modalizado por seu apagamento por outros traços que rasurem essa primeira marca. É o apagamento desse primeiro traço que significará o sujeito para outros traços que precisariam continuar a se inscrever. O sujeito é essas diversas maneiras pelas quais o traço, estranheza primeira da linguagem, é rasurado e, assim, apagado. O sujeito apaga o traço de estranheza, transformando-o em olhar, fresta, entrevisto, e, ainda, transformando-o em voz, num vagido, num esboço de fala. Assim ele pode abordar o que se passa com o outro que deixou o traço, outro que passou por ali e que está mais adiante.

A primeira alteridade do neonato é a fala endereçada a ele e não aquilo que os observadores da situação reconhecem como interferência técnica ou manipu- 


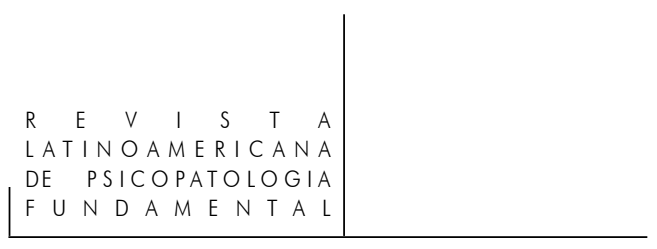

lação feita no organismo neonato. Afinal, o neonato não se distingue de seu semelhante, e nem distingue o semelhante de seu meio. Antes de distinguir os polos de onde as intervenções o atingem e mesmo de onde a fala procede e a que ela se remete, ele diferenciará a estranheza ao que é orgânico, ou seja, a alteridade da linguagem, por isso grafada Outro com maiúscula: é outro à sua natureza.

O reconhecimento da passagem do Outro será feito pelo neonato na medida em que o neonato puder ligar tal passagem a um efeito que ele manifesta, o que só ocorre se essa manifestação estiver referida ao que o agente do Outro testemunha e reconhece no neonato como atrelada a tal passagem. Ou seja, é preciso que o neonato possa fazer algo a partir da incidência do outro, e que esse outro partilhe com o neonato ter ocorrido ali uma resposta à marca que ele causou. Pode-se dizer isso também da seguinte forma: o neonato representa o que o outro deixou como marca por meio de um representante dessa passagem. Assim, o neonato faz uma rasura, um apagamento, uma "leitura" da passagem da alteridade pelo seu organismo. Entretanto, a apresentação do registro de sua rasura naquela marca do outro - rasura que se tornará sua resposta ao outro - depende de que seja reconhecida, ou seja, de que seja também relido pelo outro que a confirma ou a interroga: houve uma resposta ou terá havido uma resposta? Esse é o deslocamento que a incidência do neonato deve obter para se tornar um elemento da linguagem: seu deslocamento e sua concatenação com outros traços da linguagem efetivamente falada. Esse primeiro representante do outro produzido pelo sujeito, marca, dá origem e orienta, ou seja, põe em forma a alteridade simbólica.

O que distingue o ser falante de qualquer organismo vivo é o fato de ele poder rasurar vestígios, fazendo destes seus próprios traços, fazendo novos traços que demarcam reencontros em que ele se reconhece. Por isso, Lacan (1968-1969) diz que é suficiente que "um ser leia seu traço, para que ele possa reinscrevê-lo em outro lugar que não ali de onde ele o trouxe. Essa reinscrição é o vínculo que o torna dependente, a partir daí, do campo da linguagem" (p. 304).

Trata-se da dimensão original que inaugura o registro do sujeito como aquele que apaga seus vestígios substituindo-os por sua assinatura. A assinatura na qual o bebê pode vir a se reconhecer depende inteiramente do fato de um outro recolher e comemorar as repetições testemunhadas de um certo olhar, de um certo vagido, ou de um movimento que este reconhece como respostas, ou seja, como significantes concatenados aos seus e articulados à pulsação tensão-apaziguamento do bebê. $\mathrm{O}$ fato de o significante nascer dos vestígios apagados tem a consequência de esses traços apagados só terem valor pelos outros significantes instituídos como sistema, sejam eles parecidos ou iguais. Só aí começa o alcance pleno da linguagem. Os traços apagados são os únicos aceitos pelos outros traços. Os traços apagados contrastam com o primeiro traço, estabelecendo uma rede dife-

Rev. Latinoam. Psicopat. Fund., São Paulo, v. 13, n. 4, p. 617-634, dezembro 2010 
rencial, pois mesmo aparentemente iguais eles ocorrem numa ordem que diferencia e concatena seus lugares. Um modo de olhar ou um vagido deixam traços ali onde eles vêm a inscrever-se, no nível do outro, no que se abre para além do olhar ou da voz: o fato de um ser vivo estar envolto na linguagem, no sistema dos significantes, tem sobre ele a consequência de que as imagens visuais e sonoras são sempre mais ou menos marcadas nele, por serem assumidas como significantes no sistema.

Para dar conta desse funcionamento, é necessário considerar que a marca do agente do Outro no organismo neonato, a manifestação do neonato que rasura essa marca e a leitura efetuada pelo agente, não se distingam objetivamente para o bebê e para o cuidador. Por isso, o conceito de área intermediária da experiência, esse espaço ilusório em que se sobrepõem aquilo que o bebê pode criar e o que lhe é proporcionado, segundo Winnicott (1951, p. 390), nos fornece o modelo e a função da transmissão promovida pela linguagem, muito antes de se configurar em um primeiro objeto material de possessão, chamado transicional, como a ponta do cobertor (p. 392):

(...) Desde o nascimento, portanto, o ser humano está envolvido com o problema da relação entre aquilo que é objetivamente percebido e aquilo que é subjetivamente concebido (...) A área intermediária a que me refiro é a área concedida ao bebê, entre a criatividade primária e a percepção objetiva baseada no teste de realidade. Os fenômenos transicionais representam os primeiros estádios do uso da ilusão, sem os quais não existe, para o ser humano, significado na ideia de uma relação com um objeto que é por outros percebido como externo a este ser (p. 402). Essa área intermediária da experiência, incontestada quanto a pertencer à realidade interna ou externa (compartilhada) constitui a parte maior da experiência do bebê (...) (p. 406)

Paradoxalmente, portanto, a primeira alteridade vige no laço simbólico e, nesse momento, prescinde da diferenciação das posições objetivadas agente/neonato, mas não da articulação entre termos distintos. A água da linguagem (Lacan, 1975, p. 11), ou o zumbido do enxame significante (1972-1973, p. 196) se estabelece como campo simbólico em demasiada antecedência à localização do "dentro" e do "fora" pelo bebê, ou das posições correlativas diferenciadas bebê-cuidador, mesmo que esse campo seja agenciado pelo cuidador. O bebê entra funcionando nesse campo, "nessa nebulosa da falação que se debulha desde sempre pelo mundo" (Calligaris, 1986, p. 21), muito antes de localizar um objeto em relação a um "teste da realidade" (Freud, 1911, p. 69). Apenas depois de articular o que se engendra do funcionamento concatenado dos significantes, o sentido/ significado será configurado pelo efeito de resíduo desse funcionamento. Tratase, nesse resíduo, da falta, nomeada objeto causa, tal como formalizado por Lacan. 


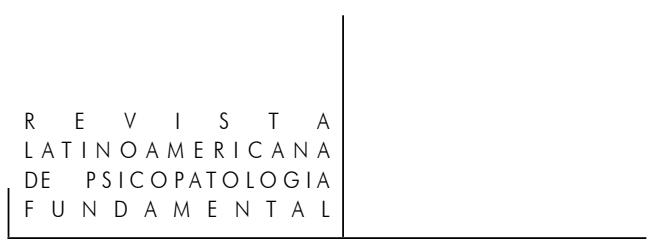

Vale ainda marcar a importância da concatenação desse funcionamento que engaja o organismo neonato na constituição subjetiva, distinguível a partir da temporalidade localizada por Lacan (1945, p. 211) como pressa. Recorro aqui a essa perspectiva da antecipação para distinguir a função da pressa, formulando e situando a presença do sujeito por meio de uma precipitação decorrente do usufruto do balizamento simbólico demarcado pelos estados alternados de tensão e apaziguamento.

Construindo uma lógica da ação e da deliberação, Lacan situa a modulação do tempo segundo três formas de subjetivação, que podemos, caso consideremos a vigência da área intermediária da experiência, localizar indiscriminadamente tanto no agente cuidador quanto no neonato: (1) sujeito impessoal no instante de ver: o outro que transitiva os estados do bebê a partir de seus próprios estados, posicionando-se interpelado e responsivo; (2) sujeito indefinido recíproco no tempo para compreender: o neonato e o outro funcionando simetricamente na diferenciação ordenada e alternante tensão-apaziguamento; e (3) sujeito da asserção no momento de concluir: o neonato. $\mathrm{O}$ sujeito da asserção é engendrado por meio da repetição de duas escansões nas quais Lacan isola a função específica da pressa: o sujeito se precipita em concluir para compensar seu atraso eventual (Porge, 2006, p. 520-521) na diacronia entre tensão-apaziguamento. Interessa aqui, portanto, focalizar a modalidade da pressa como já presente muito antes de esta se estabelecer por uma competição temporal com o outro, ou na identificação especular (como propõe o sofisma do tempo lógico de Lacan), mas como possibilidade de o próprio neonato tentar fazer vigorar o exercício alternante da oposição tensão-apaziguamento, que se remetem e se convocam biunivocamente, no gozo da vida. Podemos localizar a dimensão de antecipação entre duas escansões que coagem o sujeito a precipitar-se, de modo a sustentar a continuidade entre elas, posto que se situa entre o risco do atraso [havia algo aí, estava aí e não está mais] e o risco de adiantamento [um pouco mais ele estava, por haver podido ter estado lá] que implicariam, ambos, o sujeito perder a possibilidade de afirmar-se a tempo de manter o próprio balizamento dado pela articulação tensão/apaziguamento, sem esvair-se. É entre essas duas escansões que o sujeito neonato incide imediatamente, precipitando sua certeza em concluir na pressa, num momento de eclipse em que a certeza do sujeito é impelida por um ato de asserção antecipada.

Entretanto, se a UTI funciona maquinicamente, ou seja restrita ao bit 1-2, 2-1, da unidade mínima da comunicação, ela é maquínica e pré-subjetiva, pois o organismo somente recebe/dá configuração a esses bits de informação. O maquínico, mesmo que difira do organismo, não lhe faz exterioridade, pois mantém a indistinção entre dentro ou fora. Apenas a entrada do que lhes é exterior, agora ele mesmo alteridade em relação ao binário tensão-apaziguamento - terceiro que 
não é um 3, mas a relação entre 1-2 antes assumida pelo agente - o neonato pode vir a antever no 2 a ausência do 1 e vice-versa. Só aí se marca a entrada do sujeito no simbólico, fazendo valer, além da oposição, a função diferencial, que permite o tempo memorial (referência ao ausente) e antecipador (referência ao futuro): passa-se do tempo alternante, maquínico, sempre presente e sempre o mesmo, ao tempo do ser/sendo - conforme haja nessa passagem um retardo ou um apressamento.

Assim, só depois o sujeito verificará a sustentação da alternância já atingida ou perdida: a verificação da antecipação demonstra o hiato irredutível entre o ato em que comparece e sua verificação, hiato que localiza a dimensão da pressa (Porge, 2006, p. 521). Mas é ainda preciso salientar que tal articulação depende da sustentação do reconhecimento e do ressublinhamento da manifestação do neonato por um agente do Outro, que oferece o testemunho de que compareceram vestígios de um sujeito concatenados às suas ações de cuidador. Agora, as precipitações do neonato passam a ter vigência simbólica, ultrapassando sua condição reflexa, uma vez que servem ao laço social. Enfim, a fala, exterioridade neonato-uti, faz a concatenação que reconhece e articula um traço de sujeito pela operação de substituição significante, ultrapassando a autonomia pré-subjetiva da biunivocidade reflexa ou maquínica.

A notícia da marca da alteridade inscrita no corpo é dada pelos significantes secundários, que atestam que algo foi escavado, introduzindo no campo da alteridade a rasura do sujeito, que é um furo no Outro, doravante incompleto, não idêntico a um nem a todo. Essa rasura que marca a presença do sujeito no campo do Outro não substitui a condição anterior de ser do gozo, mas, por isso, mobiliza o ser a assimilar um saber outro que o aparelha para visar a recuperação do gozo vital puro, já perdido. Nessa dialética de engajamento do vivente no significante mantém-se, no corpo, algo de separado (Lacan, 1962-1963, p. 242). Resíduo de gozo sobrevivente do encontro com o significante, sua função será a de sustentar e mobilizar o desejo, mesmo que este seja ilusório, porque não se dirige a seu alvo suposto, mas sim ao resto constituído pela relação do sujeito com o Outro (p. 262). É o que permite distinguir "objeto do desejo" de "objeto causa de desejo".

A ordem simbólica implica uma ordenação. A primeira ordenação mínima, restrita a dois estados opostos em relação biunívoca (tensão/apaziguamento) que balizam o campo da experiência de usufruto da vida do neonato num certo ritmo que garante a inércia homeostática exige ser desdobrada, para que um sujeito compareça. A quebra da regularidade em que seus polos se alternam impelirá um sujeito a se apressar para sustentar a correlação diferencial, seja evocando que algo falta na sua contagem ou apelando à recuperação dessa contagem. O reconhecimento que responde testemunhando a imagem visual ou sonora de tal evo- 
cação produzirá uma recontagem, introduzindo mais um. Na perda do fluxo vital em que apenas gozava a vida, a remissão ao resto constituído na relação com o Outro constituirá um saber. Lacan lembra (1974-1975) que para atestar que um corpo esteja não apenas vivo, ${ }^{2}$ mas erogenizado, é necessária a introdução da alíngua, ou seja, um saber que ex-siste, que se enquista sem que se saiba em que consiste:

$\mathrm{S}_{1}$, o enxame, significante mestre, é o que garante a unidade, a unidade de copulação do sujeito com o saber. (...) O significante Um não é um significante qualquer. Ele é a ordem significante, no que ela se instaura pelo envolvimento no qual toda cadeia subsiste. (...) é algo que resta indeciso entre o fonema, a palavra, a frase, mesmo todo o pensamento. É o de que se trata no que chamo de significante mestre. (Lacan, 1972-1973, p. 196)

Essa figuração primeira do Outro, que forclui o gozo puro da vida transmitindo a linguagem, também transmite que a linguagem é furada, é desejante, pois a língua só é viva quando se dá uma mãozinha para ela (Lacan, 1975-1976, p. 129).

Por isso, enfim, o elemento fundamental do funcionamento técnico da UTI é o de não prescindir da fala dirigida à criança. Afinal, o zumbido do enxame de significantes capturados pela criança da língua efetivamente pronunciada para garantir a unidade corporal do ser, posiciona-o numa ordem de significância, fisgando-o ao marcá-lo. Mas aqui ainda se mantem a questão do que presidiria o engate dos significantes no organismo em uma UTI, uma vez que o endereçamento da fala por si só não responde ao fato de que ainda será necessária a "insondável decisão do ser".

\section{Referências}

Almeida, M. Grupo Criar-Te: a criatividade em UTI neonatal. In: Aragão, R. (Org.). $O$ bebê, o corpo e a linguagem. São Paulo: Casa do Psicólogo, 2004.

BАттікнA, E. Intervenção precoce no vínculo mãe-bebê especial em uma unidade de terapia intensiva neonatal. In: CAMARotTi, M. (Org.). Atendimento ao bebê, uma abordagem interdisciplinar. São Paulo: Casa do Psicólogo, 2001.

Bergés, J.; BALBo, G.. Jogo de posições da mãe e da criança, ensaios sobre o transitivismo. Porto Alegre: CMC, 2004.

Bernardino, L. É possível uma clínica psicanalítica com bebês? In: KuPFer, M.C.; Teperman, D. (Orgs.). O que os bebês provocam nos psicanalistas. São Paulo: Escuta, 2008. 
Bleichmar, S. As condições de humanização. In: Melgaço, R. (Org.). A ética na atenção ao bebê: psicanálise, saúde, educação. São Paulo: Casa do Psicólogo, 2006.

CATÃo, I. A mãe, o recém-nascido de muito baixo peso e a interação: uma nova perspectiva para os cuidadores da Unidade de tratamento intensivo neonatal. In: ARAGÃo, R. (Org.). O bebê, o corpo e a linguagem. São Paulo: Casa do Psicólogo, 2004.

Coniat, E. Psicanálise e clínica de bebês. Porto Alegre: Artes e Ofícios, 1997.

DiAs, M. A aventura do vir a ser: a experiência em UTI neonatal. In: ARAGão, R. (Org.). O bebê, o corpo e a linguagem. São Paulo: Casa do Psicólogo, 2004.

Fernandes, C.M. Prevenção ou antecipação?, inédito, 2003.

Freud, S. (1895). Projeto de uma psicologia científica. Tradução de Gabby Jr. Rio de Janeiro: Imago, 1995.

. (1911). Formulações sobre os dois princípios do acontecer psíquico. In:

Escritos sobre a psicologia do inconsciente. Rio de Janeiro: Imago, 2004. v. I.

(1925). Inibição, sintoma e ansiedade. In: Edição Standard Brasileira das Obras Psicológicas Completas de Sigmund Freud. Rio de Janeiro: Imago, 1976. v. XX.

Jerusalinsky, A. O nascimento do ser falante. In: Bernardino, L.; Rohenkohl, C. (Orgs.). O bebê e a modernidade, abordagens teórico-clínicas. São Paulo: Casa do Psicólogo, 2002.

KRodi, P. Cuidados paliativos em neonatologia: a escuta do indizível. In: KUPFer, M.C.; Teperman, D. (Orgs.). O que os bebês provocam nos psicanalistas. São Paulo: Escuta, 2008.

LaCan, J. (1945). O tempo lógico e a asserção da certeza antecipada. In: Escritos. Rio de Janeiro: Jorge Zahar, 1998.

. (1949). O estágio do espelho como formador da função do eu, tal como nos revela a experiência psicanalítica. In: Escritos. Rio de Janeiro: Jorge Zahar, 1998. p. 475 .

. (1973). O Aturdito. In: Outros Escritos. Rio de Janeiro: Jorge Zahar, 2003.

. (1962-3). O seminário. Livro X. A angústia. Rio de Janeiro: Jorge Zahar, 2005.

. (1968-1969). O seminário. Livro XVI. De um Outro ao outro. Rio de Janeiro: Jorge Zahar, 2008.

1982.

. (1972-1973). O seminário. Livro XX. Mais, ainda. Rio de Janeiro: Jorge Zahar,

. (1974-1975). O seminário. Livro XXII. RSI. Inédito.

. (1975-1976). O seminário. Livro XXIII. O Sinthome. Rio de Janeiro: Jorge

Zahar, 2007.

Rev. Latinoam. Psicopat. Fund., São Paulo, v. 13, n. 4, p. 617-634, dezembro 2010 


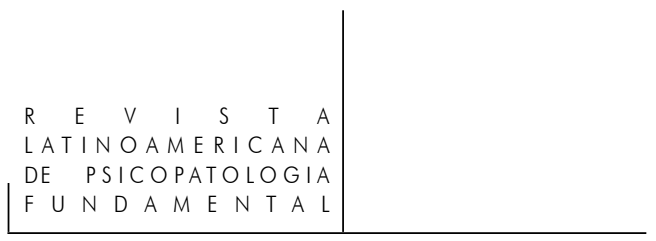

. (1975). Conferência em Genebra sobre o sintoma. Opção lacaniana, n. 23, EBP, São Paulo, 1998.

Lima, A.; Santos, A.; Sampaio, J.; Amorim, M.; Toscano M.; Leal, T. Amamentação obrigatória? Escutando mães e pediatras. In: CAmarotTi, M. (Org.). Atendimento ao bebê, uma abordagem interdisciplinar. São Paulo: Casa do Psicólogo, 2001.

Martins, A.; Vorcaro, A. A intervenção do psicanalista na clínica com bebês cirúrgicos acometidos por malformação congênita, anais do X Congresso da Abebê, Rio de Janeiro, 2007.

Porge, E. (1993). Tempo. In: Kaufmann, P. (Org.). Dicionário enciclopédico de psicanálise: o legado de Freud e Lacan. Rio de Janeiro: Jorge Zahar, 1996.

Rabello, A. A função simbólica da UTI neonatal. In: Aragão, R. (Org.). O bebê, $o$ corpo e a linguagem. São Paulo: Casa do Psicólogo, 2004.

SAnson, J. Mais uma vez, as inscrições primordiais. In: Bernardino, L. (Org.). O que a psicanálise pode ensinar sobre a criança, sujeito em constituição. São Paulo:

Escuta, 2006.

Vorcaro, A. A criança na clínica psicanalítica. Rio de Janeiro: Cia. de Freud, 1997. . Doenças graves na infância. In: Trata-se uma criança. Rio de Janeiro: Cia. de Freud, 1998. v. II.

. Linguagem maternante e língua materna: sobre o funcionamento linguístico que precede a fala. In: Bernardino, L.; Rohenkohl, C. (Orgs.). O bebê e a modernidade, abordagens teórico-clínicas. São Paulo: Casa do Psicólogo, 2002.

- A angústia nos autismos e nas psicoses infantis. Revista Literal, Campinas, 2008.

Vorcaro, A.; Lopes, J. Intervenção psicanalítica no hospital, um engodo? In: Melgaço, R. (Org.). A ética na atenção ao bebê: psicanálise, saúde, educação. São Paulo: Casa do Psicólogo, 2006.

WinnicotT, D. (1951). Objetos transicionais e fenômenos transicionais. In: Textos selecionados, da pediatria à psicanálise. 2. ed. Rio de Janeiro: Francisco Alves, 1978. p. 389-408.

ZoRnig, S. Clínica da intervenção precoce, sobre a origem e o originário. In: Melgaço, R. (Org.). A ética na atenção ao bebê: psicanálise, saúde, educação. São Paulo: Casa do Psicólogo, 2006. 


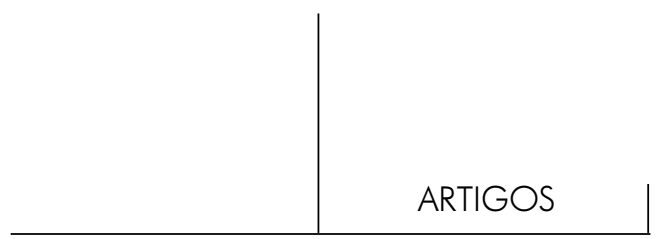

Resumos

(Subjective urgency of newborn babies in an ICU)

The objective of this article is to question certain discourses regarding the beginnings of the structuring of the subject, in order to next construct hypotheses as to what is involved in the experience of newborn babies in an ICU. For this purpose, we will compare the condition of the biological organism and medical interventions into the functions of speech and language as determinant of what will be constituted as trauma. We will also discuss how to approach the question of time in children's processes of subjectivation.

Key words: Newborn babies, psychoanalysis, ICU, language, trauma, time

(L'urgence subjective du nouveau-né en réanimation néonatal)

L'article vise à mettre en question certains discours sur les origines de la structuration du sujet pour ensuite construire des hypothèses sur ce qui serait en jeu dans l'expérience du nouveau-né prématuré en réanimation néonatale. Á cette fin, on opposera les fonctions de la parole et du langage en tant que déterminants de ce qui sera constitué comme traumatisme à l'état de l'organisme biologique et aux interventions médicales. En outre, on discutera la façon d'aborder la question du temps dans le processus de subjectivation mené par l'enfant.

Mots clés: Nouveau-né, psychanalyse, Réanimation Néonatale, langage, trauma, temps

(Urgencia subjetiva del neonato en UTI)

El artículo tiene como objetivo cuestionar algunos discursos sobre los albores de la estructuración del sujeto, para posteriormente, construir hipótesis sobre lo que estaría en juego en la experiencia del neonato prematuro en la UTI. Para eso. a la condición del organismo biológico y a las intervenciones médicas opondremos las funciones del habla y del lenguaje como determinantes de lo que se constituirá como trauma. Además, discutiremos cómo abordar la cuestión del tiempo en los procesos de subjetivación llevados a cabo por el niño.

Palabras clave: Neonato, psicoanálisis, UTI, lenguaje, trauma, tiempo

Citação/Citation: Vorcaro, A. Urgência subjetiva do neonato em UTI. Revista Latinoamericana de Psicopatologia Fundamental, São Paulo, v. 13, n. 4, p. 617-634, dez. 2010.

Editor do artigo/Editor: Prof. Dr. Manoel Tosta Berlinck

Recebido/Received: 9.10.2009 / 10.9.2009 Aceito/Accepted: 20.12.2009/ 12.20.2009

Rev. Latinoam. Psicopat. Fund., São Paulo, v. 13, n. 4, p. 617-634, dezembro 2010 
Copyright: (C) 2009 Associação Universitária de Pesquisa em Psicopatologia Fundamental/ University Association for Research in Fundamental Psychopathology. Este é um artigo de livre acesso, que permite uso irrestrito, distribuição e reprodução em qualquer meio, desde que o autor e a fonte sejam citados/This is an open-access article, which permits unrestricted use, distribution, and reproduction in any medium, provided the original author and source are credited.

Financiamento/Funding: A autora declara não ter sido financiada ou apoiada/The author has no support or funding to report.

Conflito de interesses/Conflict of interest: A autora declara que não há conflito de interesses/The author declares that has no conflict of interest.

\section{Angela Vorcaro}

Profa. Dra. do Depto. de Psicologia da Universidade Federal de Minas Gerais - UFMG (Belo Horizonte, MG, Brasil); membro dos grupos de pesquisa "Psicanálise, infância e educação" da Associação Nacional de Pesquisa e Pós-Graduação em Psicologia - ANPEPP (São Paulo, SP, Brasil) e do "Outrarte" da Universidade Estadual de Campinas - Unicamp (Campinas, SP, Brasil); membro da Association Lacanienne Internationale (Paris, França).

Rua Paul Bouthilier, 353 - Mangabeiras

30315-010 Belo Horizonte, MG

Fone: (31) 3264-4665

e-mail: angelavorcaro@uol.com.br

Rev. Latinoam. Psicopat. Fund., São Paulo, v. 13, n. 4, p. 617-634, dezembro 2010 